\title{
AN EDUCATIONAL PROGRAM ON RE-EMERGING MALARIA FOR NURSING STAFF IN A MILITARY FEVER HOSPITAL
}

\author{
By \\ MAHFOUZ AHMAD AL-AGROUDI ${ }^{1}$, LAILA ABD EL-MAWLA MEGAHED', \\ ABEER MOHAMMAD ABDALLAH ${ }^{1}$, ELHAM MOHAMMAD ABDALLAH ${ }^{1}$, \\ AND' TOSSON A. MORSY ${ }^{2}$
}

Military Medical Academy, Cairo $11291^{1}$ and Department of Parasitology, Faculty of Medicine, Ain Shams University, Cairo $11566^{2}$, Egypt

\section{Abstract}

Malaria, an Anopleles-borne protozoan parasite is of public health importance. The study aimed to improve Military nursing staff knowledge as to re-emerging malaria. Setting: The study was carried out at a Military Fever Hospital. Design: A quasi-experimental study (pre-post tests) was used. The subjects were 30 nursing staff who accepted to participate in the study pilot study was done on $10 \%$ of them. The study used composed of three tools as follows: (1) Socio-demographic characteristics of the studied Military and Educational needs assessment tool. (2) Knowledge questionnaire sheet (pre / posttest) (3) Participants 'evaluation Questionnaire sheet. Results: showed statistically significant improvements in nursing staff knowledge.

Key words: Egypt, Nursing Staff, Education, Malaria

\section{Introduction}

Malaria is an infectious by protozoan parasite transmitted by the bite of a female Anopheles spp mosquito occurs between dusk and dawn. Other comparatively rare mechanisms for transmission include: congenitally-acquired disease, blood transfusion, sharing of contaminated needles, and organ transplantation (WHO, 2011). P. falciparum was transmitted nosocomial by heparin locks (Abulrahi et al, 1997) and from patient to nurse to patient (Alweis et al, 2004).

Malaria occurs throughout most of the tropical regions of the world, with $P$. falciparum causing the largest burden of disease, followed by P. vivax (Guerra et al, 2008). P. falciparum predominates in Africa, New Guinea, and Hispaniola (Haiti and the Dominican Republic); $P$. vivax is more common in the Americas and the western Pacific. Prevalence of these two species is approximately equal in the Indian subcontinent, eastern Asia, and Oceania (WHO, 2017). P. malari$a e$ is uncommon but found in most endemic areas, especially in sub-Saharan Africa. $P$. ovale, even less common, is relatively unusual outside of Africa and comprised $<1 \%$ of isolates. $P$. knowlesi, confuses with $P$. falciparum and Babesia species in the ring form and with $P$. malariae in trophozoite form, was identified by molecular methods in patients in Malaysia, the Philippines, Thailand, and Myanmar (White, 2009). P. knowlesi cases were reported in Europe and the United States (Müller and Schlagenhauf, 2014)

The outbreak of $P$. falciparum and $P$. viv$a x$ in southern Aswan Governorate at May 2014 strongly supported the fact that malaria could reemerging in Egypt (Kenawy, 2015). Many factors contributed to the re-emergence of malaria in Egypt. Apart from the endemic focus in Al-Fayoum, local Anopheles species being in association with imported Sudanese malignant cases, continuous moving between Aswan Governorate and the Sudan as well as the influx of large population from Africa and Asia to Egyptian Governorates for University's educational and religious purposes or charging in sports activities. Another risk factor was the environmental changes brought by water-sources development projects as El Salam Canal (Hassan et al, 2003) and Toshka (Shoukry and Morsy, 2011), where El Bahnasawy et al. (2011) recorded An. multicolor, An. sergentii and An. algeriensis in Toshka. El Bahnasawy et al. (2014) added that the endemicity of chloroquine resistant $P$. falciparum on the Egyptian-Sudanese border pave the way for its transmission mainly among travelers 
returning back from Sudan. Zaher et al. (2007) reported local and imported malaria in Al-Maza Fever Hospital.

Education is the progressive discovery of knowledge and acquisition of new information, values, and skills occur continuously (Lammers and Murphy, 2002). Education has neither such finished product, nor even graduates. They are on the way "to be". Education only charges the human propensities to evolve and unfold it till the last breath, a process that covers the human journey from "womb to tomb". Human beings continue to learn, and evolve; to be (Mukhopadhyay, 2006). Thus, education about infection prevention and control was targeted as one of the main objectives of infection control program especially where nurses represent the largest group of health care workers within healthcare system (Rasslan, 2011).

Job or task-specific educations on preventing transmission of infection agent associated with healthcare during orientation to the healthcare facility are essential. Information must be updated periodically during ongoing education programs. All healthcare personnel must be targeted for education. Including but not limited to medical, nursing, clinical technicians, laboratory staff; and students. (Lau et al, 2004).

The current study aimed to evaluate an educational on malaria for nursing staff to improve nursing staff knowledge regarding re-emerging of this insect-borne protozoan risky disease.

\section{Significance of the study}

Nursing remains at the front line of patient care, satisfaction and safety by identifying and addressing patient problems in a timely fashion, improve quality, to maintain the ability of the profession to respond effectively to a dynamic health care system, the Institute of Medicine (IOMs). Future of Nursing indicated their need to practice to the fullest extent of their education, achieve higher levels of education, and become full partners in the redesign of healthcare (IOM, 2010). All the time nursing staff is the front line of health care team who face patients, so, early detection and rapid reporting which considered from Nursing "Golden Responsibilities" and utmost important for taking the decision for patient treatment and prevention. There was a lack of the knowledge, among nursing staff as to re-emerging malaria to acquaint the Egyptian military nursing staff particularly those who share with the Peacekeeping Forces to neighboring endemic countries. Therefore, it was thought that a tailored educational program would help in improving nursing staff knowledge related to this re-emerging malaria as a mosquito-borne infectious disease was selected in the current study due to their epidemiological importance.

\section{Results}

The results are shown in figures (1 to 12).

\section{Discussion}

Lack of nurse knowledge about infectious parasitic diseases, their way of transmission, symptoms and signs, ways of protection negatively affected the nature and spread of such diseases This is true with nurses going to Peacekeeping Forces in malaria endemic countries (Twum and Meredith, 2003).

The empirical study tested the hypothesis of significant positive impact of an educational program implemented on 30 nurses in a military hospital on improving their knowledge toward malaria which in turn will improve nursing care quality in general. The study was divided into 4 parts to deal with the research problems from all aspect.

Part I: Socio-demographic characteristics and educational needs assessment of the study subjects: This part included personal data such as age, sex, unit of work, educational qualifications and years of experience.

The study depicted the main characteristics that were divided to four aging groups, their age was lying between less than twenty to above forty years old and more than half of the participants were lying in the age category $(20$ - 30) years old.

All nurses were females. Nikki and Campo (2010) reported that a nurse is the feminine 
job with excellence. Nursing job in Egypt was only for females long ago and males joined this job in the last few years.

The majority of nurses $(80 \%)$ were from different units because nurses in emergency departments, operating rooms, and critical care units usually have high work load and shortage of the nursing staff.

The distribution of nurses regarding their training levels and years of experiences were included and showed that majority of them held diploma nursing school, and half of the nurses with experience $>10$ years.

From questioning nurses regarding attendance of training program about malaria, more than half of them didn't attend any training program, but only seven attended training program for less than a year. This could explain that there is no educational and training department in the hospital in addition to shortage of the nursing staff.

Part II: Knowledge levels as regards different studied topics throughout the program: This part illustrated the distribution of knowledge score among nurses throughout the study for re-emerging malaria as to definition, epidemics, causes, modes of transmission and people at risk as well as incubation period, signs, symptoms, affected organ (s), complications, diagnosis, treatment, prevention and nursing care of re-emerging malaria of pre and post-test.

The results showed a significant impact of educational sessions illuminated in the posttest on the knowledge score of nurses in all items. However, all results con- firmed on the positive impact of the educational program in improving the nurses' knowledge and there were highly statistically significant differences regarding items.

Malaria is one of the commonest parasitic disease in South Africa mainly Sub-Sahara (WHO, 2012). Malaria is transmitted by the bite of female Anopheles as well as by Needle-stick contaminated with blood from infected patient (Abdel-Motagaly et al, 2017).
Pregnant women with falciparum malaria gave the same complications as toxoplasmosis in pregnant females. Malaria diagnosis is based on clinical signs, symptoms and examining stain blood films, nursing diagnosis in malaria include impaired circulation, hyperthermia and fluid deficit a nurse should monitor vital signs Assess patient airway, breathing and respiratory condition and gave antipyretic immediately for feverish patient

This result agreed with Musa et al. (2011) who addressed that there was a strong relationship between specific educational program and knowledge acquirement and gave a significant positive effect on knowledge acquirement after taking relevant educational sessions as long as the educational or trainings program run properly. Also, the results agreed with those of Wilunda et al. (2015) in Uganda. They concluded that to reduce maternal and newborn morbidity and mortality in Karamoja Region, there was a need to increase the availability and the accessibility of skilled birth care, address the low utilization of maternity services and improve the quality of care rendered. There was also a need to improve the availability and accessibility of access to quality emergency obstetrics care services (EmOC), with particular attention to basic EmOC. There was significant improvement in nurse's staff total knowledge in post-test as compared with that pre-test and had demonstrated a positive effect of high improvement of educational program on subject's knowledge. Therefore, the use of continuing education program had successfully influenced nursing knowledge and this in-service education program turned to be effective in increasing the level of nurses' knowledge regarding the reemerging malaria. Also, Fey and Miltner (2008) found that when the knowledge score of all participants improved after the program, compared to before the program implementation, this indicated that the participants were highly interested in the program 
contents, and that the media and methods of teaching used were successful in stimulating their enthusiasm. Also, this result agreed with Tweed and Tweed (2008) who stated that the completion of the educational program gave improved level of knowledge.

Part III: Correlation between Military nursing staff knowledge regarding definition, signs, symptoms, nursing care and prevention of malaria throughout the program:

This part illustrated the correlation between military nursing staff knowledge regarding re-emerging malaria throughout the program. The study revealed that there was a highly significant positive correlation between nurses knowledge in pre and post-test as to definition, epidemics, causes, mode of transmission and people at risk and prevention of malaria this could be explained by the present program, which spot light on the importance of these topics and how can the nurse deal with it if present especially those nurses sharing in the Peace-keeping Mission and/or travel to countries were malaria is endemic. Gawthrop et al. (2012) in United Kingdom reported that nurses played an important role in advising travellers about the risk of malaria, methods of prevention and in recognizing the disease in returning travellers

Part IV: Program evaluation: This part illustrated the relation between nursing staff characteristic and knowledge throughout the program.

The study revealed that the nursing staff lying in the age group more than 30 years have got the highest total mean percentage knowledge score $(25.12 \pm 0.991)$ than other groups this could explain that; nurses usually join work at around the age of 20 years old and this a productive age that can acquire knowledge and experience easily and from age of 20 to the age above 30 nurses spent more than 10 years which increased their knowledge and experience, also the topic was not common and the nurses at this age were eager to know what is up to date. Also, in the emergency department unites, nurses have the highest total mean knowledge percent (24.75 to 1.500 ). This could explain the ED that there were a lot different cases with different diagnoses that helped nurses to improve knowledge about malaria

The study revealed also that bachelor degree and nurses staff have got the highest (total knowledge) score $(26.00 \pm 0.00)$; this could explained that university graduates have more knowledge be their basic nursing education and nurse with experience 10-15 years have got the highest total mean percentage knowledge score $(26.00 \pm 0.00)$, definitely the longer the time the nurse work the more experience she acquired.

Generally, there were statistically significant in relation between the nursing staff characteristics, age unit of work qualification, experience years and knowledge level. This result was in contrary with Yan et al. (2006) who found significant difference among age group occupational and experience regarding the knowledge improvement after educational program

The empirical study tried to test the hypothesis of the significant positive impact of the educational program implemented on 30 nurses in a military hospital on improving their knowledge toward re-emerging malaria which in turn would improve nursing care quality in general.

The study were divided into the following parts to deal with all aspects of disease and are rarely fatal, although deaths have been reported in the setting of $P$. vivax and $P$. knowlesi infections (Cox-Singh et al, 2008). Njuguna et al. (2015) in Kenya stated that the over-diagnosis of malaria cases hampers malaria control in developing countries. Due to lack of diagnostics, febrile cases are treated using signs and symptoms. They concluded that the intervention reduced overdiagnosis and overtreatment of malaria cases Kangoye et al. (2016) reported that the targeted malaria control interventions are expected to be cost-effective. Clinical, parasitological and serological markers of malaria transmission were used to detect malaria tra- 
nsmission hotspots. Success of the training program depends directly upon the satisfaction of recipients from program all sides as tutor, materials, and place; a key performance indicator (Dow et al, 2006). Power (2000) gave the main criteria of effect tutor; preparation, a positive optimistic outlook, passion, open mindedness, and reliability.

The present study showed that, the tutors had an excellent "competence with the scientific curriculum", repeating and stressing on important topics" and Encourage learning by being friendly and patient with trainees $(100 \%)$. About $(50 \%)$ considered the tutor very good as a professional and well organized. Violino (2001) stated that satisfaction with training and development was a major factor in decisions regarding peoples' careers. Guskey (2002) concluded that if the educator didn't give attention to the trainees' needs this will make a gap between both of them Azer (2003) reported that if the tutor was not efficient in the scientific contents that would make the trust of trainees hesitate and the outcome un-satisfactory. Thibault (2003) reported that when the educator was not respondents to the questions and expectations of the trainees this would make them disjoin him and value of the literature decrease markedly Prideaux (2004) mentioned that if the tutor didn't prepare for the session and read the contents even if he used to teach this literature this would make him not satisfactory enough. Chen and Silverthorne (2008) reported that it was very important to meet the expectations of the trainees in order to reach goals the program. In addition if the program and expectations of the audience didn't meet this means great gap between the objectives and outcome,

As to the evaluation of training materials/ teaching, distribution of scientific notes got $100 \%$. Also, the aids information and maintenance to the audience, the nurses preferred handouts or notes that help the trainees to remember the information. Nurses $(83.3 \%)$ considered the scientific materials as an excellent help, and (20\%) of them evaluate visual and hearing as very good. Amuwo and Jenkins (2006) found that the training materials specifically the electronic one should be clear, easy understood clear font, easy to be used by the educator or the trainees. Also, Randall (2007) found that the proper training materials should be suitable to the contents, and the audience, should cover all topics, has to be attractive, and the trainees, should get handouts and brief notes about the subject.

As to the lecture duration, $(63.3 \%)$ of them considered the lecture duration and allowing group discussion was excellent. Also, 56.7\% found that the time allowed for answering questions was excellent. But, $40 \%$ found that lecture duration was good. Gills (2001) reported that the lecture duration shouldn't be very short, not to make the trainees take it lightly or too long, not to make them bored. Smith and Poland (2003) noticed that the trainees in the first half an hour of the lecture got the maximum level of concentration with better understanding, and then concentration started to decline markedly with high impact on the abilities to understand and focus.

As to the training room, about $56.7 \%$ of the nurses found that it was very good well equipped and clean and $46.7 \%$ found that providing the room with computer devices was fair. Giachello et al. (2001) reported that the training place should be well ventilated, well lightened, comfortable furniture and equipped with materials for training contents. Jamal (2004) reported that the training room must be near or very available to the trainees. Furnham and Christoforou (2007) found that the design of the training place must reach the message for example the U-shaped tables proved very good in discussion, problem solving and interaction between the groups.

As to trainees' expectations regarding the educational program; $56.7 \%$ of them strongly agreed that the educational program met their expectations, and 50\% said that they would apply the learned knowledge. All 
nurses agreed that they were informed with the intended learning outcomes and further evaluated after their fulfillment; nurses $(50 \%)$ agreed that program content was organized and easy to follow, and (83.3\%) agreed that the lectures were useful \& related to the program title. This agreed with Borna and White (2003) that if tutor succeeded to reach expectations this proved good performance. Nursed $(71.3 \%)$ found all the topics were important, Kracher and Marble (2008) found that if the program tutor, contents, material were good this would make all topics important to the audience.

\section{Conclusion}

The educational program had succeeded in enhancing the nurses' knowledge regarding re-emerging malaria and the quality nursing care is the out-come. Nurses showed great enthusiasm toward the educational program, which enabled the Tutor to enjoy the working environment during educational session, strong communications between the tutor and trainees successfully enrich their knowledge, skills which in turn. Help them to practice nursing care in a professional way.

The study contributed significantly to the literature in the relevant field and it can trigger more research work in the future. The educational program showed significant improvement in nursing staff knowledge.

Thus, it is expected that this improvement in nursing staff knowledge would have the positive impact on the dealing with malaria prevention and control.

\section{Recommendations}

The following were suggested:.

1- There must be an educational and training department in all hospitals to develop and implement educational and training program ms for nurses to update and improve their knowledge and skills.

2- Nurses must be encouraged for self-study done by bonus, promotions or incentives.

3- There should be mandatory educational \& training programs about infectious diseases as malaria for all military nurses who will share in the Peacekeeping Missions
4- There should be health instructions about malaria and prevention particularly the mosquito-vector for the community by media and different public health care settings.

5- Travelers or immigrant-workers to endemic countries must be medical advice about preventive measures and proper chemoprophylaxis. When back to Egypt from endemic countries, they must be clinical and laboratory examined.

6- Pregnant women are risky group; malaria can be a life threatening for mother and fetus. The risk of stillbirth, spontaneous abortion, and other adverse pregnancy outcomes is increased in the setting of malaria, and the pregnant travelers should be advised to defer travel until after delivery whenever feasible.

\section{References}

Abdel-Motagaly, AME, Ibrahim, AMA, Morsy, TA, 2017: An intervention program on blood protozoa acquired by needle stick injury and infection control. J. Egypt. Soc. Parasitol. 47, 2: 309-22

Abulrahi, HA, Bohlega, EA, Fontaine, RE, Al-Seghayer, SM, Al Ruwais, AA, 1997: Plasmodium falciparum malaria transmitted in hospital through heparin locks. Lancet, 349:23-5.

Alweis, RL, DiRosario, K, Conidi, G, Kain, K C, Olans, R, et al, 2004: Serial nosocomial transmission of Plasmodium falciparum malaria from patient to nurse to patient. Infect. Cont. Hosp. Epidemiol. 25:55-9

Borna, S, White, G, 2003: Sex and gender: Two confused and confusing concepts in the "Women in Corporate Management" Literature. J. Business Ethics 47:89-99.

Chen, JC, Silverthorne, C, 2008: The impact of locus of control on job stress, job performance and job satisfaction in Taiwan. Leadership Organ. Develop. J. 29, 572-582.

Dow, K, Alexander S, Offer, T, Jeff, W, 2006: Antecedents and consequences of user satisfaction with e-mail systems. Int. J. Collab. 2, 2:46-64 El-Bahnasawy, MM, Dabbous, HKh, Morsy, TA, 2010: Imported malaria as the threaten to Egypt. J. Egypt. Soc. Parasitol. 40, 3:773-87.

El-Bahnasawy, MM, Soliman, SA, Morsy, T A, 2014: Training nurses on dealing with arthropod-borne infectious diseases: Is it a mandatory nowadays in Sub-Saharan-Africa? Egyptian Millitary Medical Journal (EMMJ) 69, 1:32-50. 
Fey, MK, Miltner, RS, 2000: A CompetencyBased Orientation Program for New Graduate Nurses. Joan Lippincott Williams \& Wilkins Inc. Gawthrop, M, Stillwell, A, Wong, CS, Simons, H, 2012: Preventing malaria in travellers: An overview. Nurs. Times 108, 21:23-5

Guerra, CA, Gikandi, PW, Tatem, AJ, et al, 2008: The limits and intensity of Plasmodium falciparum transmission: Implications for malaria control and elimination worldwide. PLoS Med. 5:e38.

Hassan AN, Kenawy MA, Kamal, H, AbdelSattar AA, Sowilem, MM, 2003: GIS-based prediction of malaria risk in Egypt. East. Mediterra. Hlth. J. 9, 4:548-58.

IOM, 2010: Institute of Medicine; The future of nursing: Leading change, advancing health: Report recommendations. http://www.iom.edu/ media/Files/Report0/\%Files

Jamal, M, 2004: Burnout, stress and health of employees on nonstandard work schedules: a study of Canadian workers. Stress Hlth. 20:113-9.

Kenawy, AM, 2015: Review of Anopheles mosquitoes and malaria in ancient and modern Egypt. Egypt. Acad. J. Biol. Sci. 8, 1:15-32.

Kangoye, DT, Noor, A, Midega, J, Mwongeli, J, Mkabili, D, et al, 2016: Malaria hotspots defined by clinical malaria, asymptomatic carriage, PCR and vector numbers in a low transmission area on the Kenyan Coast. Malar J. 2016 Apr. 14;15:213. doi: 10.1186/s12936-016-1260-3.

Lammers, WJ, Murphy, JJ, 2002: A profile of teaching techniques used in the university classroom. Active Learn. High. Educat. 3, 1:54-67.

Müller, M, Schlagenhauf, P, 2014: Plasmodium knowlesi in travellers, update 2014. Int. J. Infect. Dis. 22:55-64.

Mukhopadahyay, M, 2006: Total Quality Management in Education; Sage, New Delhi, India.

Musa, AH, Bahaman, AS, Hayrel, A, Mohammed, S, Jeffrey L, 2011: Socio-demographic factors affecting attitude towards information and communication technology usage. Amer. J. Appl. Sci. 8, 6:553-9.

White, NJ, 2008: Plasmodium knowlesi: the $5^{\text {th }}$ human malaria parasite. Clin. Infect. Dis. 46: 172-8.

Njuguna, J, Menge, D, Nzou, J, Chege, C, 2015: Impact of an intervention to minimize overdiagnosis of malaria cases in a low risk Kenyan sub-county. J. Hlth. Care Poor Underserved 26, 3:802-10

Power, AG, 2000: Insect transmission of plant viruses: A constraint on virus variability. Curr. Opi. Plant Biol. 3:336-340

Rasslan, O, 2011: Infection prevention and control education in Egypt: professional diploma in infection control (PDIC). Int. J. Infect. Control 7:i2 doi: 10.3396/ijic. V7i2. 015.11

Shoukry, NM, Morsy, TA, 2011: Arthropod borne diseases at Toshka, Upper Egypt. World J. Zool. 6, 2:126-33.

Smith, SA, Poland, GA, 2003: Immunization and the prevention of influenza and pneumococcal disease in people with diabetes. Diabetes Care 26, 1:S126-8.

Thibault, GE, Neill, JM, Lowenstein, DH, 2003: The academy at Harvard Medical School: Nurturing teaching and stimulating innovation. Acad. Med. 78:673-81

Tweed, C, Tweed, M, 2008: Intensive care nurses' knowledge of pressure ulcers: Development of an assessment tool and effect of an educational program. Am. J. Crit. Care 17:338-46.

Violino, B, 2001: Still in the money. Network Computing 12, 16:66-70.

WHO, 2011: World Malaria Report. file://www. who.int/malaria/world_malaria_report_2011/en/. WHO, 2017: Malaria, Fact sheet: from http:// www.who.int/ mediacentre/factsheets/fs094/en/

Wilunda, B, Ng, N, Stewart Williams, J, 2015: Health and ageing in Nairobi's informal settlements-evidence from the International Network for the Demographic Evaluation of Populations and Their Health (INDEPTH): A cross sectional study. BMC Publ. Hlth. 15:1231-9.

Zaher, T, Ahmedi, M, Ibrahim, A, El-Bahnasawy, M, Gouda, H, et al, 2007: Malaria in Egypt, Saudi Arabia and Yemen: a clinical pilot study. J. Egypt. Soc. Parasitol. 37, 3:969-76.

\section{Explanation of figures}

Fig. 1: Socio-demographic characteristics of military nursing staff as regard age.

Fig. 2: Socio-demographic characteristics of military nursing staff as regard unit work.

Fig. 3: Socio-demographic characteristics of military nursing staff regarding educational qualification.

Fig. 4: Socio-demographic characteristics of military Nursing staff regarding years of experience..

Fig. 5: Training status of nursing staff and their educational needs on malaria

Fig. 6: Measuring level of nursing staff knowledge as to definition, epidemics, causes, mode of transmission, and people at risk in pre and post-test

Fig. 7: Measuring level of nursing staff knowledge as to incubation period signs, symptoms, malaria affecting organs pre and post -test

Fig. 8: Measuring level of nursing staff knowledge as to complications, diagnosis and treatment of malaria in pre and post- test

Fig. 9: Measuring level of nursing staff knowledge regarding nursing care of malaria $(\mathrm{N}=30)$

Fig. 10: Measuring level of nursing staff knowledge of study regarding prevention of malaria in pre and post- test $(\mathrm{N}=30)$

Fig. 11: Evaluation of tutor $(\mathrm{N}=30)$ 
Fig 12: Evaluation of training materials/teaching aids regarding as visual/hearing

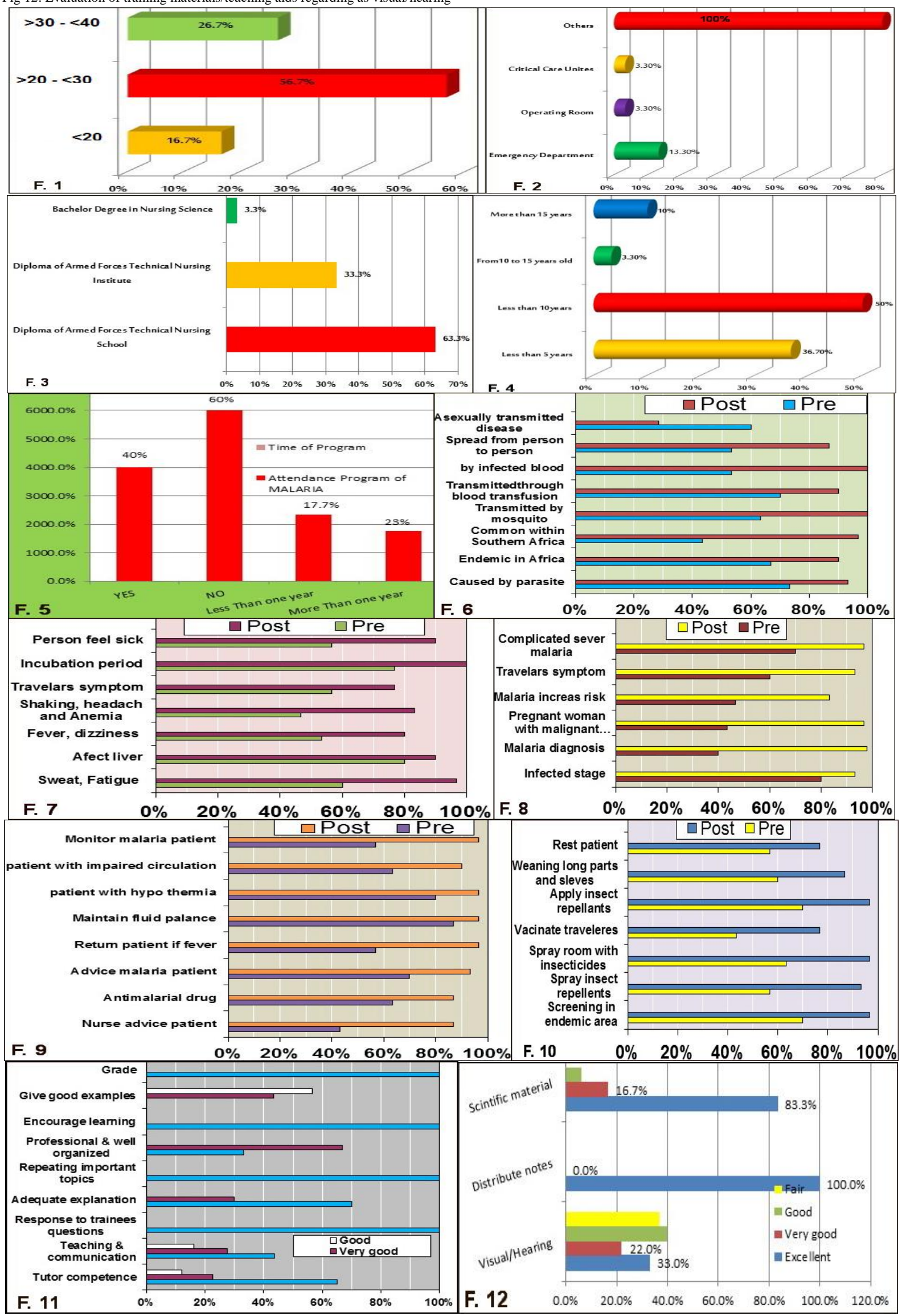




\title{
VARIATION OF MORPHOMETRIC TRAITS WITHIN POPULATIONS OF GROUND BEETLES ANTHIA SEXMACULATA (COLEOPTERA: CARABIDAE) LOCATED IN DIFFERENT ECOGEOGRAPHICAL REGIONS IN EGYPT
}

By

\author{
MOSTAFA I. HASSAN ${ }^{1}$, DALIA A. ELSHEWY², AHMED S. BREAM ${ }^{1}$, \\ AND SABER A. RIAD ${ }^{1 *}$
}

Department of Zoology, Entomology Unit, Faculty of Science ${ }^{1}$, Al Azhar University, Nasr City, Cairo, and Department of Insect Classification and Survey ${ }^{2}$, Plant

Protection Research Institute, ARC, Dokki, Giza, Egypt. ( ${ }^{\star}$ Correspondence:saberiad60@azhar.edu.eg, Tel. 20201000262403)

\section{Abstract}

The morphometric measurements of populations of Anthia sexmaculata in different regions were studied in Egypt. A multivariate comparison of morphometric differences was undertaken by eyepiece micrometer on three different ecogeographical areas in Egypt; Western Mediterranean Coastal Desert (WMCD) (North Coast, Fouka and Mersa Matruh), Western Desert (Siwa, Bahariya and Dakhla Oases) and South Sinai (Saint Catherine and Taba Protected area and Sharm El Sheikh wadis). Twenty-one morphometric traits were studied. Traits best corresponding to the distinction of populations was distinguished by cluster and discriminant analysis (LDA). The first and second discriminant axes (Axis1 and Axis2) recorded 88.38\% and 11.62\%, respectively, of the total variation in studied sample. Multiple discriminant analysis revealed clear morphometric differences between West Mediterranean Costal Desert, Western Desert and South Sinai populations. Traits connected with morphometric measurements are good characters for differentiation between carabid beetles, South Sinai population of A. sexmaculatus have been shown to differ morphologically from the other populations in Egypt.

Key Words: Egypt, Biogeography, Morphometrics, Linear Discriminant Analysis, Anthia sexmaculata, Carabid beetle,

\section{Introduction}

Egypt occupies the northeastern part of the Africa. It is roughly quadrangular, extending about $1073 \mathrm{~km}$ from north to south and about $1229 \mathrm{~km}$ from east to west. Thus, the total area of Egypt is a little more than one million square kilometers $\left(1,019,600 \mathrm{~km}^{2}\right)$ occupying nearly $3 \%$ of the total area of Africa (Abu Al-Izz, 1971). The position of Egypt amongst the faunal regions of the world is a rather anomalous one, since it combines the characteristics of both Palaearctic and Afrotropical regions. It has generally been considered to belong to Palaearctic, but the Afrotropical element is much greater than usually thought (Steyskal and El Bialy, 1967). Egypt is a part of the Great Desert Belt and it is characterized by warm and almost rainless climate. Only the Coastal Strip, Gebel Elba and high mountains of southern Sinai receive comparatively higher rainfall. This is reflected on their floral and faunal composition (Larsen, 1991). Egypt is into 8 ecological zones; The Coastal Strip, Lower Nile Valley and Delta, Upper Nile Valley, El Faiyum Depression, Eastern Desert, Western Desert, Gebel Elba and Sinai (El Hawagry and Gilbert, 2014).

Within insect species, the size of each organ, appendage or body regions bears a specific relationship to overall body size (Shingleton et al, 2007). Positive correlations have been found between wings and body size, fore-femur length and body size, and body size and morphological traits associated with feeding mandibles, head (Stern and Emlen, 1999). These correlations, head width or mandible length are related to an ability to consume larger food items (Pearson and Stemberger, 1980). Such a positive relationship between feeding morphology and body size differed among populations because of dis- 